\title{
Legionella-associated lung abscess: Critical pathogen or minor isolate?
}

\author{
GORDON CK DOW, MD, FRCPC, ANTHONY W CHOW, MD, FRCPC, FACP
}

\begin{abstract}
GCK Dow, AW CHow. Legionella-associated lung abscess: Critical pathogen or minor isolate? Can J Infect Dis 1992;3(6):315-318. Two cases of lung abscess, in which Legionella species were identified in association with other bacterial isolates, are presented. In the first case, Legionella pneumophila and Klebsiella pneumoniae were identified in a 24-year-old post renal transplant patient with a right upper lobe pulmonary abscess. Healing did not occur until the institution of specific therapy directed against legionella. In the second case, Legionella micdadei and several other respiratory bacterial pathogens were identified in a 74-year-old woman with a lung abscess. The patient later died with multisystem failure despite adequate antimicrobial therapy. Prior cases of legionella-associated lung abscess have occurred predominantly in corticosteroid-treated patients. The role of coexisting bacterial isolates remains obscure.
\end{abstract}

Key Words: Legionella micdadei, Legionella pneumophila, Lung abscess

\begin{abstract}
Abcès pulmonaires liés à Legionella: pathogène important ou phénomène isolé?
RÉSUMÉ: Deux cas d'abcès pulmonaires dans lesquels l'espèce la Legionella ont été identifiés en association avec d'autres isolats bactériens sont présentés. Dans le premier cas, Legionella pneumophila et Klebsiella pneumoniae ont été identifiés chez un patient de 24 ans qui présentait un abcès pulmonaire du lobe supérieur droit après une transplantation rénale. La quérison n'est survenue qu'après l'amorce d'un traitement dirigé spécifiquement contre Legionella. Dans le second cas, Legionella micdadei et divers autres pathogènes bactériens respiratoires ont étê identifiés chez une femme de 74 ans, présentant un abcès pulmonaire. La patiente est décédée quelque temps après à cause de déficiences pluri-systémiques, en dépit d'un traitement antimicrobien indiqué. Les premiers cas d'abcès pulmonaires liés à Legionella se sont produits surtout chez des patients traités aux corticostéroïdes. Le rōle d'isolats bactériens coexitants reste imprécis.
\end{abstract}

Division of Infectious Diseases, Department of Medicine. University of British Columbia and Vancouver General Hospital, Vancouver, British Columbia

Correspondence and reprints: Dr Anthony W Chow, Division of Infectious Diseases, Vancouver General Hospital. 2733 Heather Street, Vancouver, British Columbia V5Z 1 M9

Received for publication May 14, 1991. Accepted November 28, 1991 
$\mathrm{L}$ EGIONELLA PNEUMOPHILA AND LEGIONELLA MICDADEI ARE the most common human pathogens within the family Legionellaceae. Both organisms typically cause pneumonia; each also is capable of a self-limited nonpneumonic febrile illness (Pontiac fever and Lochgoilhead fever, respectively). Pneumonia can occur with coinfection by both agents (1). Abscess formation is a rare complication of legionellosis. Two cases in which pulmonary cavitation was a major clinical presentation of legionella infection are reported. The incidence of this under-recognized complication of legionellosis is reviewed, and its diagnostic and therapeutic implications are discussed.

\section{CASE PRESENTATIONS}

Case 1: A 24-year-old male, who had been a renal transplant recipient four years previously, presented with three-week history of fever and cough. He had a past medical history of asthma and alcohol abuse, and smoked 10 cigarettes per day. Medications were cyclosporine $90 \mathrm{mg}$ twice daily and prednisone $20 \mathrm{mg}$ on alternate days. On examination he was in no distress; the respiratory rate was $22 / \mathrm{min}$ with generalized expiratory wheezing. Chest $\mathrm{x}$-ray showed a right upper lobe cavity (Figure 1). Bronchoalveolar lavage fluid, obtained from this lobe at bronchoscopy, grew Klebsiella pneumoniae. Anaerobes were not isolated. Monoclonal direct fluorescent antibody specific for $L$ pneumophila (Genetic Systems, Washington) showed positive staining on this specimen, but the organism was not cultured. The patient responded to a two-week course of

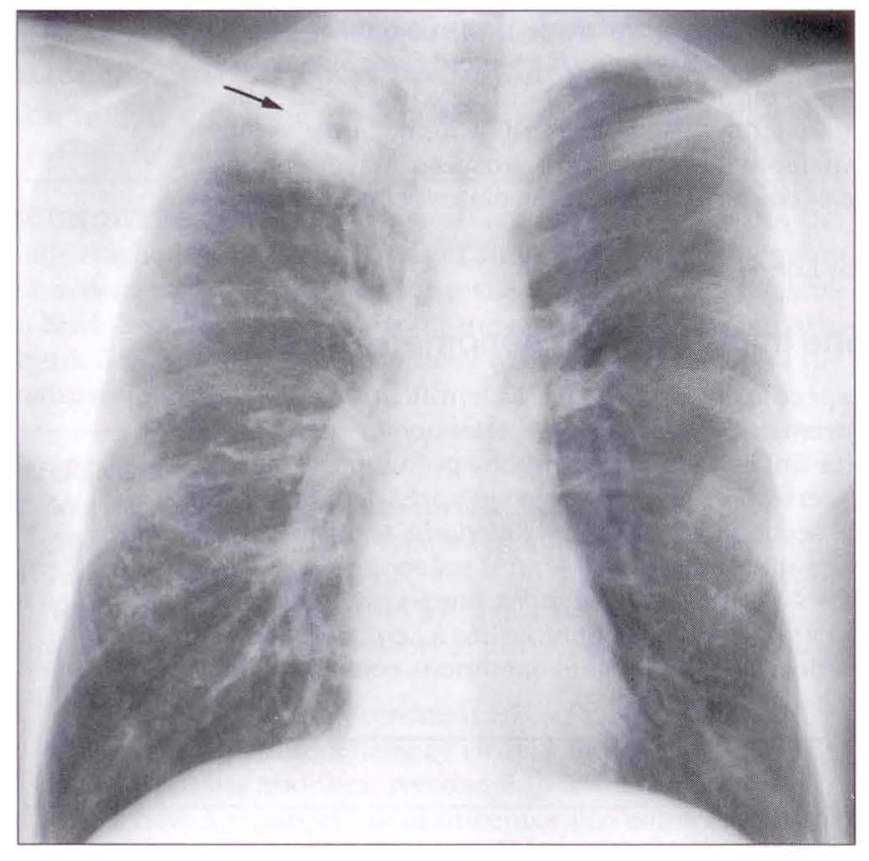

Figure 1) Postero-anterior view of the chest radiograph of patient 1 performed on admission to hospital. Note the well-circumscribed radioluscent cavity located in the apex of the right upper lobe. A prior chest radiograph was normal erythromycin $500 \mathrm{mg}$ intravenously four times daily, but relapsed while taking oral ciprofloxacin $500 \mathrm{mg}$ twice daily as an outpatient. Ciprofloxacin was continued with the addition of erythromycin and rifampin with complete resolution of the abscess cavity.

Case 2: A 74-year-old woman was admitted with a one-week history of fever, malaise, cough and myalgia, and a one-day history of dyspnea. Past medical history was positive for hypertension, ischemic heart disease and transient ischemic attacks. There was no history of tuberculosis, recent travel or smoking. Medications included diuretics and amoxicillin for the previous day. The patient had a temperature of $38^{\circ} \mathrm{C}$ and a respiratory rate of $44 / \mathrm{min}$. Mild neck stiffness and delirium were noted. There was bronchial breathing at the left base and chest $\mathrm{x}$-ray demonstrated lingular consolidation. Arterial blood gases obtained on room air showed: $\mathrm{pH}$ 7.41: $\mathrm{PCO}_{2} 26 \mathrm{mmHg} ; \mathrm{PO}_{2} 52 \mathrm{~mm}$ of bicarbonate, 17 $\mathrm{mmol} / \mathrm{L}$. The patient was hyponatremic and in renal failure (serum creatinine $324 \mu \mathrm{mol} / \mathrm{L}$ ). Fibrotic bronchoscopy was performed; bronchoalveolar lavage fluid grew L micdadei, Staphylococcus aureus, Haemophilus influenzae, group G streptococci and coliforms. Anaerobes were not isolated. Treatment with erythromycin $500 \mathrm{mg}$, cloxacillin $1 \mathrm{~g}$ and ampicillin $1 \mathrm{~g}$, each every 6 $\mathrm{h}$, was given intravenously. The patient required mechanical ventilation late on the day of admission and by the fifth hospital day, an extensive cavity was noted in the lingula (Figure 2). The patient later developed anuric renal failure, and peripheral gangrene of the toes and fingers. She died on day 12 .

\section{DISCUSSION}

Lung abscess is an uncommon complication of $L$ pneumophila pneumonia. While this disease has an estimated incidence of 12 cases per 100,000 per year. only 40 cases of abscess formation have been described (2-12).

The first patient represents a probable case of $L$ pneumophila pneumonia with abscess formation. Although the organism was not cultured, L pneumophila antigen was detected. The monoclonal immunofluorescent antibody used to identify $L$ preumophila has been shown to have weak cross-reactivity only to Staph aureus and occasional Lactobacillus species. Neither species was cultured from this patient. Culture-negative, direct fluorescent antibody-positive cases were present in some of the cases reviewed (in which the diagnosis was confirmed serologically). The presence of legionella in the patient was supported further by a rapid clinical response to erythromycin alone during initial therapy, and by subsequent relapse while receiving an agent that would have been active against $K$ preumoniae.

This post renal transplant patient was also typical of most reported cases of legionella-associated lung abscess, in which 90\% (37 of 40) were immunocom- 
promised. Most patients were being treated with corticosteroids when lung abscess was diagnosed (33 of 44, 80\%). Although cytotoxic immunosuppressive agents may also be present, they have not been implicated as a risk factor when used in isolation. Legionellae are facultative intracellular pathogens, and likely it is corticosteroid-induced impairment of cell-mediated immunity, particularly monocyte-lymphocyte function, which increases host susceptibility to these organisms (11). Senecal and co-workers (5) have shown that these patients are characterized by nosocomial acquisition of pneumonia $(73 \%)$, prior solid organ transplantation (44\%), rapid progression to abscess formation over one to two weeks, slow radiological evidence of healing and a high mortality rate (30\%). These patients fail to show the usual older age distribution and male predominance of most groups who acquire legionellosis, reflecting the importance of depressed immunity as a key risk factor.

$L$ micdadei is an uncommon cause of pneumonia but has a greater propensity to cause abscess formation. Of the 104 evaluable cases of $L$ micdadei pneumonia which have been reported since 1977,11 cases $(10.5 \%)$ of pulmonary cavitation have been documented previously (13). Ten of these patients acquired pneumonia while in hospital and were being treated with corticosteroids before its advent. The second case reported here is unusual in that $L$ micdadei was associated with abscess formation in a host who neither had nosocomial pneumonia nor was obviously immunocompromised except for her age. One prior case of $L$ micdadei pneumonia has been reported where abscess formation occurred in the absence of corticosteroid use (14).

Macroscopic abscess formation at autopsy was not always evident radiologically in the 51 cases reviewed, suggesting that the overall incidence of pulmonary cavitation in legionellosis may be underestimated. This same incidence probably is overestimated by autopsy studies, which may select for a population more likely to have lung abscess. One such study (15) demonstrated abscess formation in 24\% (10 of 42) of patients with $L$ preumophila and 55\% (five of nine) of those with $L$ micdadei.

The role of legionella in pulmonary cavitation has been obscured by the presence of other pathogens or by the failure to describe microbiologic investigations more completely. Analysis of the 40 cases previously described demonstrated $L$ pneumophila as the sole isolate in 14 (35\%). These cases used culture techniques aimed at recovery of anaerobic, fungal and mycobacterial pathogens. In another seven cases (17\%), other pathogenic bacteria were recovered, while incomplete data were available for the remaining 19 cases (48\%). It is possible that bacterial copathogens played a dominant role in those cases in which they were identified. Broad spectrum antibiotics, used before the isolation of legionella, also may have eradicated other bacterial

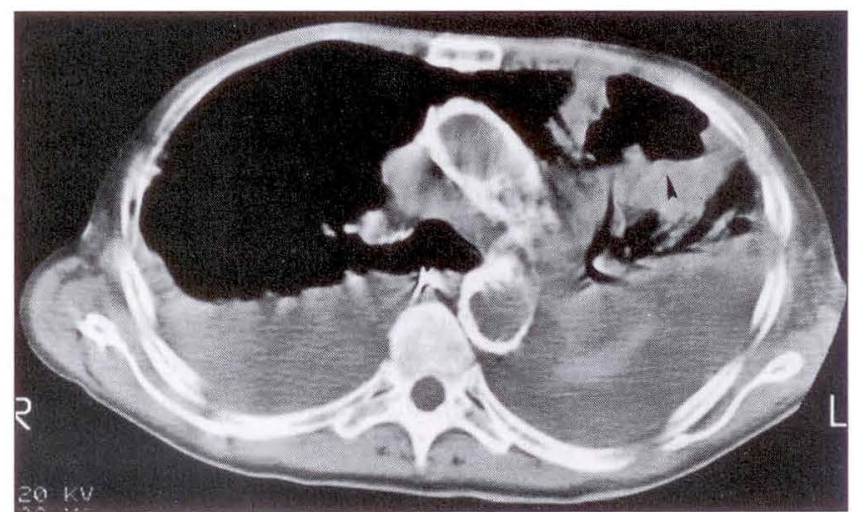

Figure 2a) Computed tomographic scan of the chest of patient 2 obtained on the seventh hospital day showing an abscess cavity (arrow) with an area of lingular consolidation and large bilateral pleural effusions

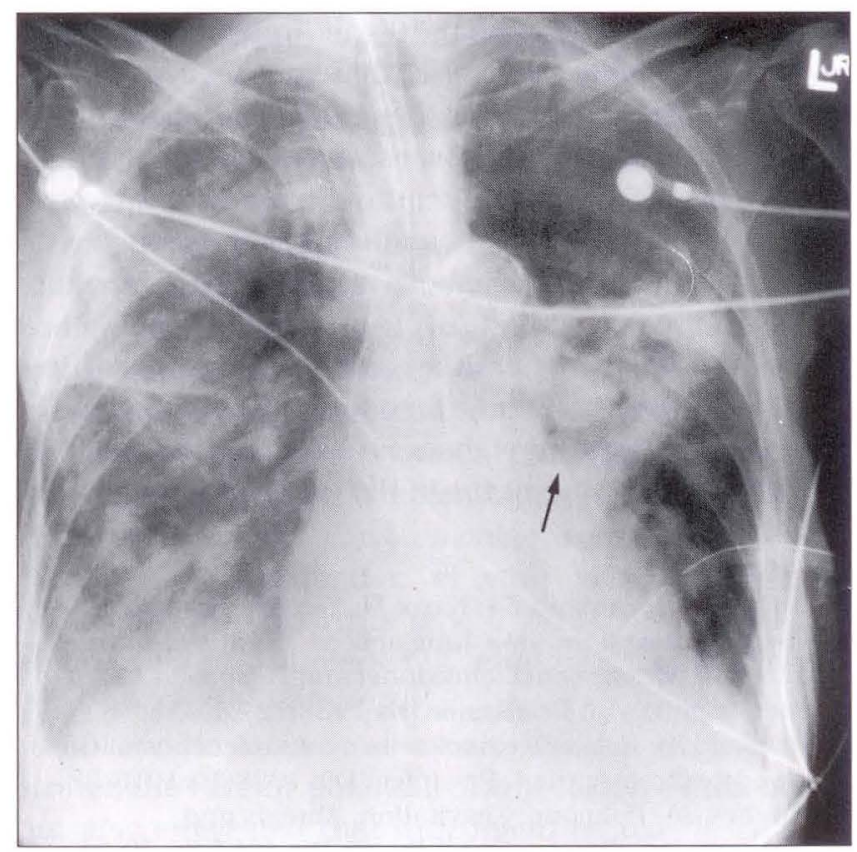

Figure 2b) Antero-posterior view of the chest radiograph of patient 2 obtained on the 12th hospital day showing consolidation and abscess formation within the lingula (arrow), bilateral alveolar infiltrates and extensive arterial calcification

copathogens in cases where only legionella was isolated. However, there is strong evidence that legionella as a sole pathogen may cause pulmonary cavitation. It has been isolated in pure culture by invasive techniques (eg, open lung biopsy or percutaneous lung aspiration) in cases in which the duration of previous antibiotic therapy would be unlikely to have eliminated other copathogens. In many cases, patients continued to deteriorate on antibiotic regimens adequate for most bacterial pathogens, while recovery occurred only with the addition of erythromycin. Survival has been associated with use of erythromycin, while in nonsurvivors, its use was either withheld, delayed or 
inadequate (5). On the other hand, investigations for Legionella species may be delayed because of the presence of other bacterial pathogens, leading to unnecessary morbidity and mortality.

In cases in which isolation of legionella are associated with a polymicrobial infection, each bacterial species may contribute to the pathogenesis of lung abscess. A symbiotic relationship may exist between legionella and other copathogens, as has been demonstrated between $L$ preumophila and $H$ influenzae (16).

Lung abscess has been viewed traditionally as a polymicrobial infection, often with a high incidence of anaerobes, occurring in patients at high risk of aspiration (17). However, legionella-associated lung abscess often occurs in patients as a single pathogen; anaerobes are rarely isolated and aspiration has not been shown as the principal mode of transmission. Is legionella lung abscess a unique entity? Probably not, as recent data suggest that $50 \%$ of lung abscesses can be monomicrobial, and less than one-half of monomicrobial cases contained anaerobic pathogens (18). The microbiology of lung abscess varies with the patient population. Nosocomially acquired lung abscess in immunocompromised hosts has not been well-studied as an isolated group. The above findings may be more typical of these patients.

Muder (19) has offered a convincing argument implicating aspiration as a mode of transmission in legionellosis. However, abscess formation in legionellosis does not always occur in the usual sites typical for

\section{REFERENCES}

1. Dowling JN, Kroboth FJ, Karpf M, Yee RB, Pasculle AW. Pneumonia and multiple lung abscesses caused by dual infection with Legionella micdadei and Legionella pneumophila. Am Rev Respir Dis 1983:127:121-5.

2. Reingold AI. Role of legionellae in acute infections of the lower respiratory tract. Rev Infect Dis 1988:10:1018-28.

3. Hughes JA. Pulmonary cavitation, fibrosis and Legionnaires' disease. Eur J Respir Dis 1985;66:59-61.

4. Bauling PC, Weil R, Schroter G. Legionella lung abscess after renal transplantation. J Infect 1985;11:51-5.

5. Senecal JI, St Antoine P, Believeau C. Legionella pneumophila lung abscess in a patient with systemic lupus erythematosus. Am J Med Sci 1987;293:309-14.

6. Frits-Moller A. Treatment of legionella lung abscess in a renal transplant recipient with erythromycin and fusidic acid. Eur J Clin Microbiol 1985;4:513-5.

7. Wilczed H, Kallings I, Nystrom B, Hoffner S. Nosocomial Legionnaires' disease following renal transplantation. Transplantation 1987;43:847-51.

8. Dobranowski J, Stringer D. Diagnosis of legionella lung abscess by percutaneous needle aspiration. Can Assoc Radiol J 1989:40:43-4.

9. Wright JB, Athor KA, van Olm TM, Wottlift JS, Costerton JW. Atypical legionellosis, isolation of Legionella pneumophila serogroup 1 from a patient with aspiration pneumonia. J Hosp Infect 1989; 13:187-90.

10. Pillemer SR, Webb WD, Yocum DE. Legionnaires' disease in a patient with rheumatoid arthritis treated with cyclosporine. J Rheumatol 1989;16:117-20. aspiration pneumonia and appears to have a different anatomic distribution from typical legionella pneumonia (in which there is predominant lower lobe involvement). Aspiration cannot be considered a proven mechanism in either situation thus far.

Legionella infection should be pursued as a cause of lung abscess in those patients with underlying immunodeficiency, particularly if they are receiving corticosteroids or failing to respond to conventional treatment. Since it is rare, it probably does not need to be strongly considered in other circumstances of pulmonary cavitation. Optimal therapy is unknown, but most patients require erythromycin, $4 \mathrm{~g}$ daily intravenously, for a minimum of three weeks or until an adequate clinical response is achieved, followed by a course of oral erythromycin. Rifampin has been advocated for its potential synergistic effect, but reports of its added benefit in lung abscess so far are only anecdotal.

\section{CONCLUSIONS}

In summary, evidence implicating $L$ pneumophila and $L$ micdadei as significant pathogens in pulmonary abscess formation in immunocompromised patients has been presented. A literature review suggests that this complication may occur with greater frequency with $L$ micdadei. While the contribution of other bacterial species, when isolated, remains unknown in legionellaassociated lung abscess, their presence should not obviate a search for coexisting Legionella species in the immunosuppressed host.

11. Lefaux NM, Sekla L, McLeod J, et al. Epidemic of nosocomial Legionnaires' disease in renal transplant recipients: A case-control and environmental study. Can Med Assoc J 1989;1940:1047-53.

12. Saravolatz LD, Burch KH, Fisher E, et al. The compromised host and Legionnaires' disease. Ann Intern Med 1979:90:533-7.

13. Fang GD, Yu VL, Vickers RM. Disease due to the legionellaceae (other than Legionella pneumophila). Historical, microbiological, clinical and epidemiological review. Medicine 1989;68:116-32.

14. Ackley AM. Community-acquired Legionella micdadei pneumonia. Lancet 1981;8213:221.

15. Winn WC, Myerowitz RL. The pathology of the legionella pneumonias: A review of 74 cases and the literature. Hum Pathol 1981;12:401-22.

16. Stout JE, Best MG, Yu VL, Rihs JD. A note on symbiosis of Legionella pneumophila and Tatlochia micdadei with human respiratory flora. J Appl Bacteriol 1986:60:297-9.

17. Bartlett JG, Gorbach SL, Tally FP, Finegold S. Bacteriology and treatment of primary lung abscess. Am Rev Respir Dis 1974:109:510-8.

18. Grinan NP, Lucena FM, Romero JU, Michavilu IA, Dominguez SU, Alia CF. Yield of percutaneous needle lung aspiration in lung abscess. Chest 1990:1:69-74.

19. Muder BR, Yu VL, Woo AH. Mode of transmission of Legionella preumophila. Arch Intern Med 1986; 146:1607-12. 


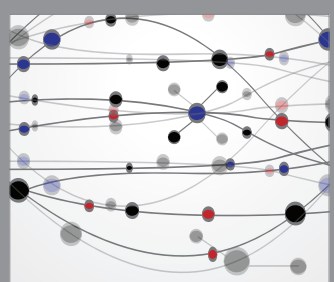

The Scientific World Journal
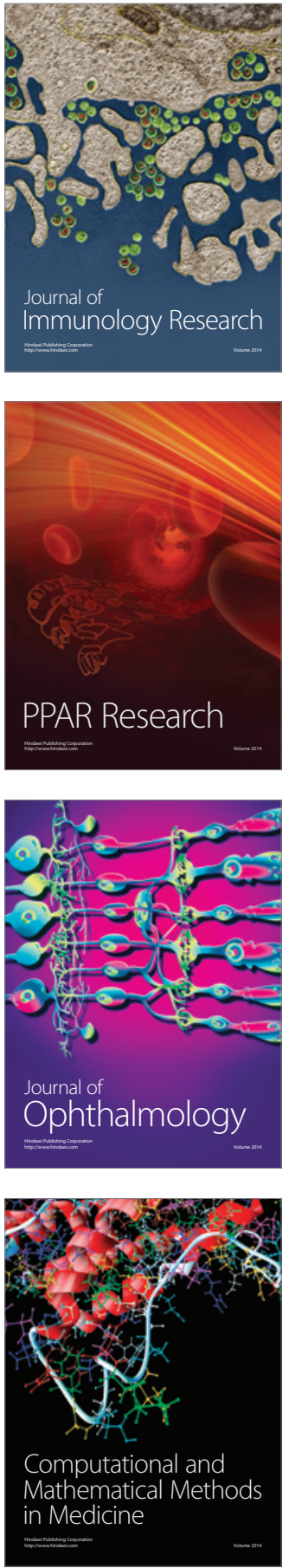

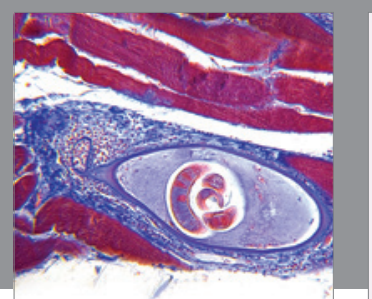

Gastroenterology Research and Practice

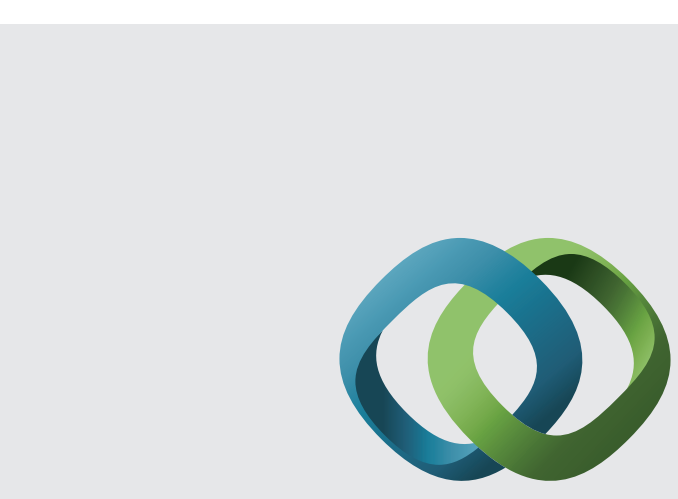

\section{Hindawi}

Submit your manuscripts at

http://www.hindawi.com
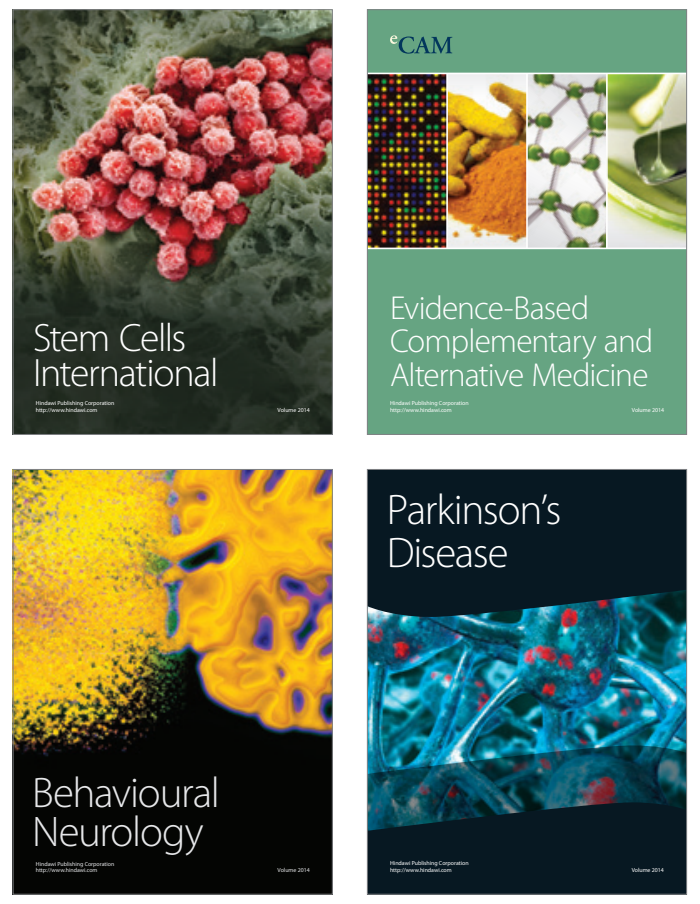
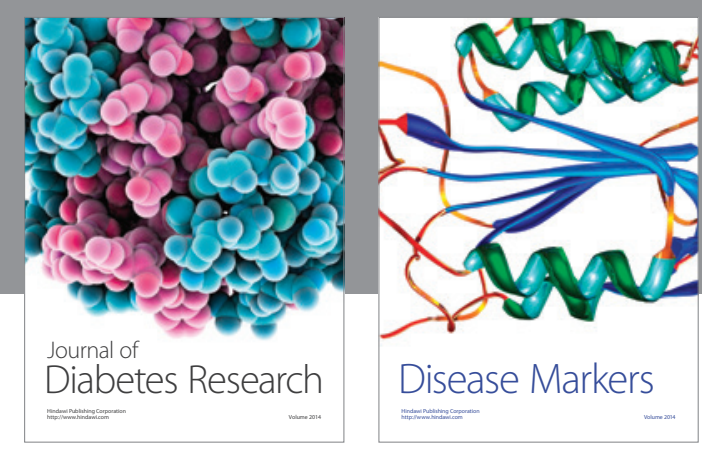

Disease Markers
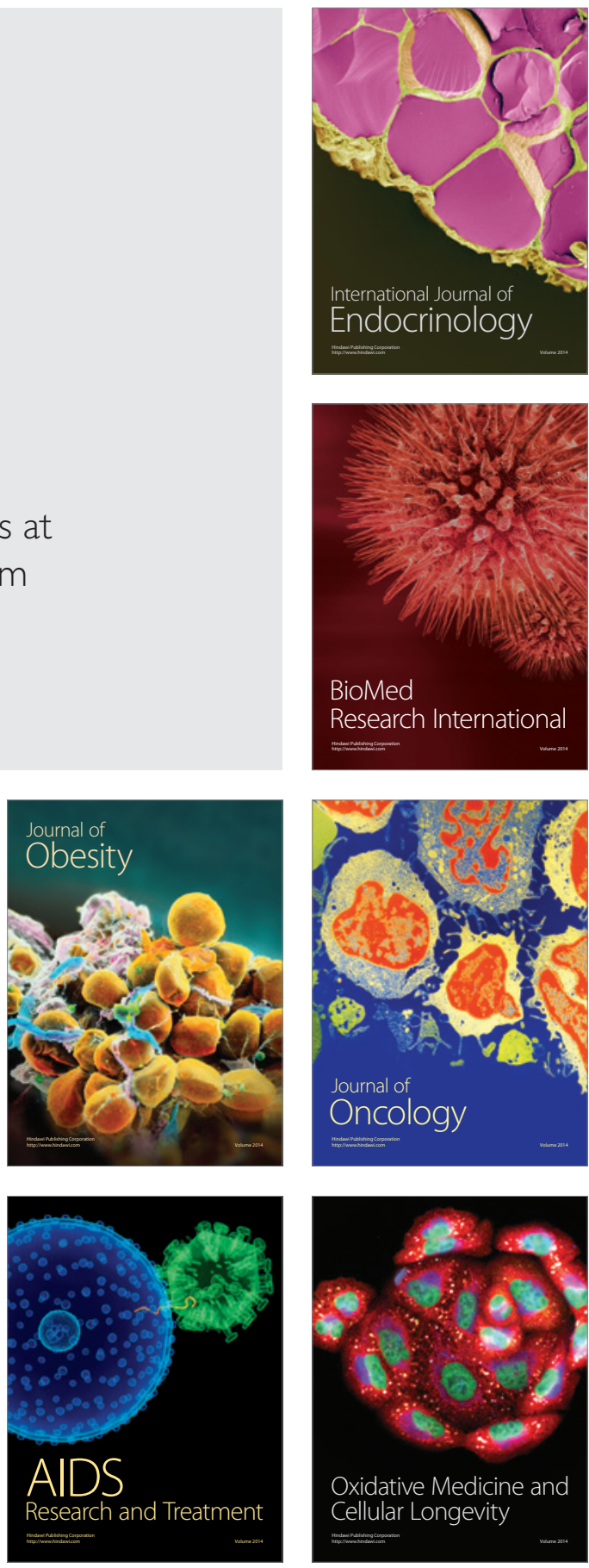